\title{
Scanning Ion Conductance Microscopy (SICM) for Low-stress Directly Examining of Cellular Mechanics
}

Petr Gorelkin ${ }^{1}$, Alexander Erofeev ${ }^{2}$, Vasilii Kolmogorov ${ }^{2}$, Yuri Efremov ${ }^{3}$, Pavel Novak ${ }^{2}$, Andrew Shevchuk $^{4}$, Alexander Majouga ${ }^{2}$ and Yuri Korchev ${ }^{4}$

${ }^{1}$ Medical Nanotechnology; National University of Science and Technology MISiS, Moscow, Moskva, Russia, ${ }^{2}$ National University of Science and Technology "MISIS"; Lomonosov Moscow State University, Moscow, Moskva, Russia, ${ }^{3}$ I.M. Sechenov First Moscow State Medical University (Sechenov University), Moscow, Moskva, Russia, ${ }^{4}$ Imperial College London, London, England, United Kingdom

The ability to precisely move the nanopipette and to measure simultaneously an ion current allows an unprecedented level of nanoscale imaging of living cells - scanning ion conductance microscopy (SICM)(Korchev et al., 1997). The speed of data acquisition increased by hopping protocol of scanning (Novak et al., 2009) positions this as a technology which may be suited to relatively high-speed scanning of cell membrane during various biological processes in real time. SICM imaging is not limited to topographical studies but also for functional properties studying in combination with other techniques such as confocal and fluorescence microscopy (Novak et al., 2014), electrochemical measurements (Erofeev et al., 2018), chemical mapping (Zhang et al., 2019) and patch-clamp recording (Novak et al., 2013). This has the potential to open new horizons in medicine and biology and could be of particular value to the pharmaceutical industry.

Recently it was shown that SICM can be used for examining of cellular mechanics by applying pressure through the pipette (Rheinlaender \& Schäffer, 2013). The main disadvantage of this method is the size of the pipette. Reasonable value of pressure applied on a sample can be achieved only for pipettes with submicron diameter $(400-1000 \mathrm{~nm})$. However, a high resolution of topography images is possible to achieve with sharp nanopipettes with diameter less than $200 \mathrm{~nm}$. It is possible to use nanopipettes with diameter less than $100 \mathrm{~nm}$ for low-stress cellular mechanics investigation due to applying low stress on cell surface (Clarke et al., 2016), whose nature is intrinsic colloidal pressure between nanopipette tip and cell membrane. A glass nanopipette out of contact with the plasma membrane can be used for both exert the stress on the cell and also accurately monitor cellular compression. This allows the mapping of cell stiffness at a lateral resolution finer than $100 \mathrm{~nm}$. We have examined both with SICM and atomic force microscopy (AFM) how various cellular compartments influence on cellular stiffness such as a nuclear, microtubules and actin filaments. We have demonstrated a correlation between values of cellular stiffness measured by low stress SICM and AFM.

We have demonstrated unique application of SICM for directly examining subcellular mechanics. we use a glass nanopipette out of contact with the plasma membrane to both exert the stress on the cell and also accurately monitor cellular compression. This allows the mapping of cell stiffness at a lateral resolution finer than $100 \mathrm{~nm}$. We have examined both with SICM and atomic force microscopy (AFM) how various cellular compartments influence on cellular stiffness such as a nuclear, microtubules and actin filaments. We have demonstrated a correlation between values of cellular stiffness measured by low stress SICM and AFM.

We have estimated the value of an intrinsic colloidal pressure and its dependence on size of nanopipettes by measuring of deformations of decane oil drops in liquid induced by interaction between nanopipette 
and saline-oil interface (Figure 1). Also, we have compared the data obtained with SICM and Peak-Force AFM on soft polymer sample.

We report cell stiffness measurements of drug-induced alterations in cancer cell compartments studied by SICM, specifically, we analysed human prostate cancer cell line PC3 subjected with Paclitaxel for microtubulin stabilization, monomethyl auristatine $\mathrm{E}$ for microtubule depolymerisation (Figure 2a) and Cytochalasin-D for actin depolymerization (Figure 2b). In control and treated PC3 cells we measured cell stiffness upon the nucleus area and cytoplasm area, which are show two different values in control cells $(\sim 1.3 \mathrm{kPa}$ and $\sim 0.8 \mathrm{kPa}$, respectively). Measured stiffness after Paclitaxel treatment shows significantly increased stiffness value on central area and peripheries area $(\sim 4 \mathrm{kPa}$ and $\sim 1.8 \mathrm{kPa})$, whereas Cytochalasin$\mathrm{D}$ treatment reduced cell stiffness only on cytoplasm area $(\sim 0.5 \mathrm{kPa})$. As we can see, SICM measurements of stiffness show different effects of Paclitaxel/monomethyl auristatin E and Cytochalasin-D on cancer cell compartments, including actin and microtubulin, respectively. Drug-induced disruptions of these cell compartments lead to cell mechanical properties alteration, depending on inhibition mechanism.

a)

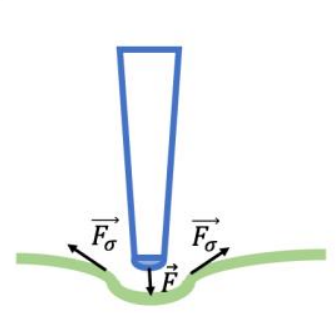

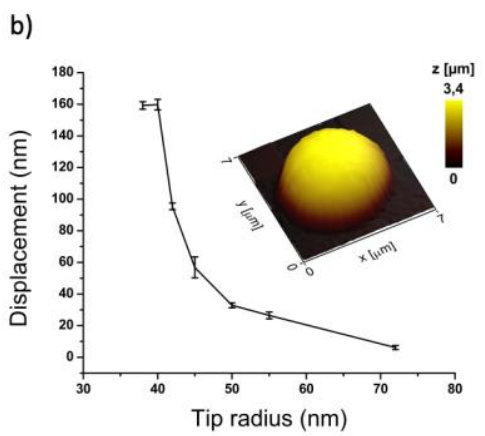

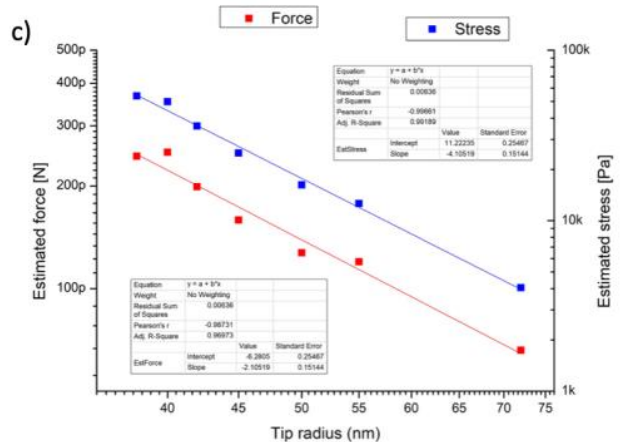

Figure 1. a) Scheme of interaction of nanopipette with saline-oil interface, b) Dependence of depth of saline-oil interface deformation on nano pipette radius, c) Dependence of intrinsic colloidal pressure and force on radius of nanopipette

a)
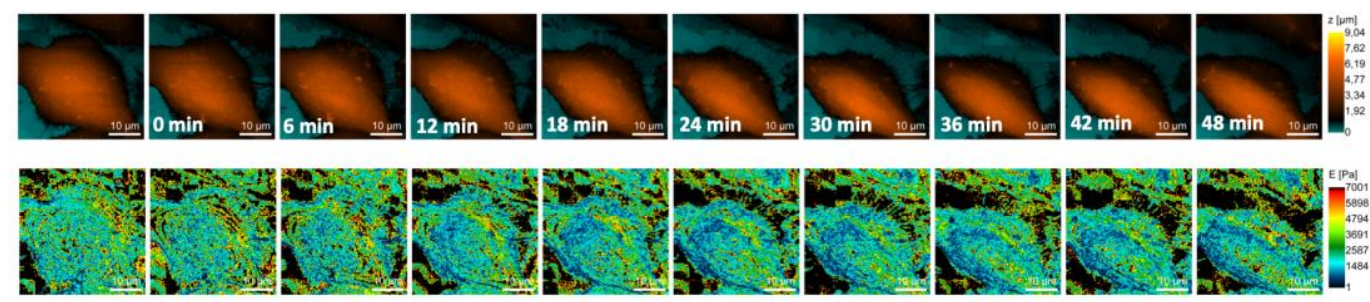

b)

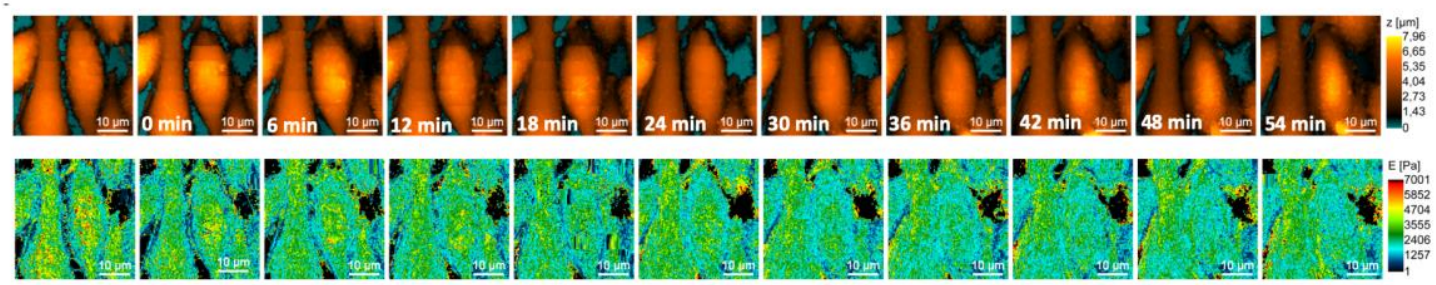


Figure 2. a) Topography and stiffness images of PC3 cells after treatment with cytochalasin D, b) Topography and stiffness images of PC3 cells after treatment with monomethyl auristatin E

\section{References}

Clarke, R. W., Novak, P., Zhukov, A., Tyler, E. J., Cano-Jaimez, M., Drews, A., Richards, O., Volynski, K., Bishop, C. \& Klenerman, D.(2016). Soft Matter 12, 7953-7958.

Erofeev, A., Gorelkin, P., Garanina, A., Alova, A., Efremova, M., Vorobyeva, N., Edwards, C., Korchev, Y. \& Majouga, A. (2018). Scientific Reports 8, 7462.

Korchev, Y. E., Bashford, C. L., Milovanovic, M., Vodyanoy, I. \& Lab, M. J. (1997). Biophysical Journal 73, 653-658.

Novak, P., Gorelik, J., Vivekananda, U., Shevchuk, A. I., Ermolyuk, Y. S., Bailey, R. J., Bushby, A. J., Moss, G. W. J., Rusakov, D. A., Klenerman, D., Kullmann, D. M., Volynski, K. E. \& Korchev, Y. E. (2013). Neuron 79, 1067-1077.

Novak, P., Li, C., Shevchuk, A. I., Stepanyan, R., Caldwell, M., Hughes, S., Smart, T. G., Gorelik, J., Ostanin, V. P., Lab, M. J., Moss, G. W. J., Frolenkov, G. I., Klenerman, D. \& Korchev, Y. E. (2009). Nature Methods 6, 279-281.

Novak, P., Shevchuk, A., Ruenraroengsak, P., Miragoli, M., Thorley, A. J., Klenerman, D., Lab, M. J., Tetley, T. D., Gorelik, J. \& Korchev, Y. E. (2014). Nano Letters 14, 1202-1207.

Rheinlaender, J. \& Schäffer, T. E. (2013). Soft Matter 9, 3230.

Zhang, Y., Takahashi, Y., Hong, S. P., Liu, F., Bednarska, J., Goff, P. S., Novak, P., Shevchuk, A., Gopal, S., Barozzi, I., Magnani, L., Sakai, H., Suguru, Y., Fujii, T., Erofeev, A., Gorelkin, P., Majouga, A., Weiss, D. J., Edwards, C., Ivanov, A. P., Klenerman, D., Sviderskaya, E. V., Edel, J. B. \& Korchev, Y. (2019). Nature Communications 10, 5610.

\section{Acknowledgements}

Experiments on PC3 cells were supported by the Ministry of Education and Science of the Russian Federation in the framework of increase Competitiveness Program of NUST "MISIS", implemented by a governmental decree dated 16th of March 2013, No 211. Russian Science Foundation (grant no. 19-1900626) supports the work related to evolution of intrinsic colloidal forces. 